\title{
A LITERATURA DE FOLHETOS NORDESTINOS E A RELIGIOSIDADE POPULAR
}

\author{
Adriano Carvalho Viana ${ }^{1}$
}

RESUMO: A proposta deste artigo é delinear a literatura de folhetos nordestinos, genuinamente brasileira e definir suas características próprias que são a oralidade e a versificidade. Os ciclos da literatura de folhetos são distintos entre si, sendo o ciclo religioso o de maior ênfase, pois traz consigo, o pietismo popular do povo nordestino. Ressalta-se a figura do poeta Patativa do Assaré. Os procedimentos metodológicos foram: evidenciar o catolicismo como uma fonte rica de nossa cultura religiosa, e como o eixo da religiosidade popular nas classes simples do Brasil se expande pelas benzedeiras, rezadeiras e "ladainhas". Nas linhas gerais, o trabalho informa o leitor sobre essa preciosa literatura que tem traços culturais: regionais e religiosos em sua formação, quais os seus primeiros passos e como continua a se expande por todos os estados. Exalta-se a religiosidade e sua repercussão. Valorizando assim nossa cultura pela piedade popular de modo através da literatura de Folhetos Nordestinos.

Palavras Chaves: Cordel, Folhetos Nordestinos, Religiosidade, Criatividade

\begin{abstract}
The proposal of this article is to delineate the literature of northeasterns booklets, genuinely Brazilian and which its proper characteristic that is the orality. The cycles of the literature of booklets are distinct between itself, being the religious cycle of greater emphasis, therefore it brings I obtain, the popular pietism of the people northeastern. It is standed out figure of the Patativa poet of the Assaré. The metodológicos procedures had been: to evidence the catholicism as a rich source of our religious culture, and as the axis of the popular religiosidade in the simple class of Brazil it expands for the folk healers, mourners and "litanies". In the general lines, the

\footnotetext{
1 Formando em Filosofia, pelo Centro Universitário Assunção, atual PUC- São Paulo, Especialista em Educação pelo FATEH e Mestrando em Docência e Gestão da EducaçãoAdministração Escolar e Administração Educacional pelo Instituto Lusófono de Educação Superior
} 
work informs the reader about precious literature that has cultural traits: regional and religious its formation, which its first steps and as it continues it expands for all the states. Exaltas to religiosity and its repercussion. Thus valuing our culture for the popular mercy in way through the literature of Northeasterns booklets.

KEYWORDS: Twine, Northeasterns booklets, Religiosity, Creativity.

\section{INTRODUÇÃO}

O objetivo geral da pesquisa é ressaltar a importância da literatura de folhetos nordestinos. Através da religiosidade popular é algo que nasce do povo, é como o povo se relaciona com o transcendente sem interferência institucional, é a expressão religiosa de um povo, que se faz pela transmissão de avós para netos, de pais para filhos com orações e devocionários. Perpetua a tradição e a expressão popular de fé.

A relevância do trabalho pode ser considerada de protuberante importância, pois demonstra Frei Francisco van der Poel $^{2}$, OFM, conhecido carinhosamente como frei Chico, conta que no Vale do Jequitinhonha, um padre, ao comentar a reza das benzedeiras, disse: Essas mulheres inventam cada uma!". Não sabia ele que a reza destas mulheres tem mais de mil anos, e que boa parte do missal em latim prescrito no Concílio Tridentino ainda não tem 500 anos.

A problemática da pesquisa centra-se na diferença: o povo traz consigo sua piedade peculiar, seu jeito de se comunicar e se correlacionar com o universo, a natureza e o próprio grupo social. E corroboram com os mais velhos antigos têm em si uma experiência que se sobrepõe aos estudos, nunca sequer tiveram acesso às carteiras escolares, mas com uma sabedoria profunda, com suas orações e rituais, transmitem sua fé com simplicidade e singularidade.

Concluindo, artigo irá fazer você percorrer um caminho cheio de dilemas e contextualização: será o nordeste brasileiro desnudo ao olhar e percepção do leitor. Realçando os traços significativos para a formação cultural brasileira de folhetos, unificando versos com a realidade, metrificação com a contextualização e trazer a

\footnotetext{
${ }^{2}$ Holandês radicado no Brasil, há décadas dedica-se e está imerso na religiosidade popular. Pode ser considerado "doutor honoris causa" no tema. É autor do livro Com Deus me deito, com Deus me levanto, coletânea de orações populares e reflexões a respeito. Publicou em 2012 o extenso volume Dicionário da religiosidade popular.
} 
história para perto do leitor. Os folhetos têm uma única e fundamental característica: transmitir a cultura e a religiosidade de um povo simples, de forma simples e eficaz.

Siga-me neste percurso com ardente desejo e com os pés calçados de preferência com sandálias rasteiras e traga água para sua sede, pois o caminho é longo. Caminhemos!

\section{Epifania de devoção e fé}

A religiosidade é manifestação de fé e propagação do itinerário humano, que busca na simplicidade da vida, no jeito humilde, ter confiança em Deus e continuar propagando suas orações, rezando e confiando que um dia encontrará neste Deus o repouso e a paz eterna. Talvez, sem conhecer a Agostinho, o povo tenha a convicção que fomos feitos para Deus e só descansaremos quando nos voltarmos para ele.

A piedade do povo vai em duas direções: a Deus e ao próximo, pois além da prática das orações e de outros rituais de forma laica, o povo mantém a solidariedade e o cuidado para com os outros, pastoreando-se a si mesmo. Para criar e recriar o sertão com as figuras "iconizadas" e demonstrar a política e religião se entrelaçando com prosa e versos.Descreve Procópio:

Há um catolicismo 'Santorial', um catolicismo 'erudito ou oficial', um catolicismo dos 'reafiliados'. Marcado pela inserção num 'regime forte de intensidade religiosa', (CEBs, RCC) e um emergencial catolicismo midiático. O Catolicismo santorial é uma das formas mais tradicionais de Catolicismo presente no Brasil desde o período da colonização. Tem como característica central o culto aos santos, foi esse culto que marcou a peculiar dinâmica religiosa brasileira... O catolicismo brasileiro foi durante muito tempo um catolicismo de 'muita reza e pouca missa, muito santo e pouco padre'. (PROCÓPIO: 1999, p. 32)

Papa Francisco vem durante seu pontificado enfatizando a importância sublime da religiosidade do povo, que faz com que a fé não se perca, mesmo com a secularização da atualidade. Ele frisa que a religiosidade é uma mantenedora da piedosa crença de um povo simples e que fixa essa piedade popular. Diz o Papa Francisco (2013): 
Não convém ignorar a enorme importância que tem uma cultura marcada pela fé, porque, não obstante os seus limites, essa cultura evangelizada tem, contra os ataques do secularismo atual, muito mais recursos do que a mera soma dos crentes. Uma cultura popular evangelizada contém valores da fé e solidariedade que podem provocar o desenvolvimento de uma sociedade mais justa e crente, e possui uma sabedoria peculiar que devemos saber reconhecer com olhar agradecido (PAPA FRANCISCO,2013, p.47).

É nítido que a religiosidade propagada e piamente usada pelo povo simples, e que contém traços de uma relação profunda de sua fé com Deus, não é uma mera invenção e sim um legado que se propagou ao longo do tempo. É um culto simples, mas assumido e celebrado em aliança com Deus. Ao pé da cama, rezam: Com Deus me deito, com Deus eu me levanto, com a graça de Deus e do Espírito Santo. (Oração do Devocionário popular).

Dessa forma, mantém sua autonomia em relação à religião institucionalizada, mas estabelece relações de respeito e fraternidade com seus membros. Como nos ensina Rodrigues (1980):

Um catolicismo das devoções populares mantinha uma relativa autonomia com respeito ao catolicismo institucional. Não havia uma oposição aos padres, e quando estes apareciam - por ocasião das desobrigas ou missões populares - eram acolhidos e festejados. Mas a dinâmica dessa religiosidade 'dispensava' a presença dos representantes oficiais da igreja, gozando, assim, de ampla liberdade. Como mostrou Carlos Brandão, em determinadas ocasiões o povo 'ocupava o padre' para certas bênçãos ou rituais de passagem, mas o resto da vida de fé ficava mesmo por conta dos 'recursos miúdos dos objetos simbólicos da fé' dos agentes religiosos populares (RODRIGUES: 1980, pp.125-126)

\subsection{A arte de versejar no devocionário católico popular}

O catolicismo popular se desenvolve a partir da religiosidade onde o clero não marcou presença, sendo anterior à presença do catolicismo oficial, representado pelo 
clero. Trata-se de um conjunto de crenças e rituais comuns a um povo piedoso, que venera a Deus de forma sincrética, mantendo uma tradição de fé como parte de sua cultura, visão de mundo ou mentalidade geral.

O catolicismo popular é fruto de um espírito ou de uma mentalidade devocional do povo, revela o caráter da religião popular e visa oferecer fé e cultura através da tradição religiosa. Os santos de devoção são homens comuns com qualidades e defeitos, porém suas virtudes podem elucidar o povo.

Aqui falamos de Padre Cícero (CE), Antônio Conselheiro (CE), Frei Damião (Itália-Recife), ou até mesmo das maiores manifestações religiosas que acontecem no Santuário de Nossa Senhora de Nazaré (Belém- PA) e em Bom Jesus da Lapa (BA).

São figuras muito conhecidas e de presença marcante na sociedade, tornam-se ícones que são aclamados pela fé popular e por sua ousadia em defender o povo oprimido. Padre Cícero e Antônio Conselheiro, por exemplo, foram homens que deixaram suas marcas na História e na Cultura, e mesmo distante cronologicamente, tornam-se próximos devido ao seu carisma, à sua ousadia e ao seu espírito de luta em defesa do povo pobre e simples do sertão nordestino.

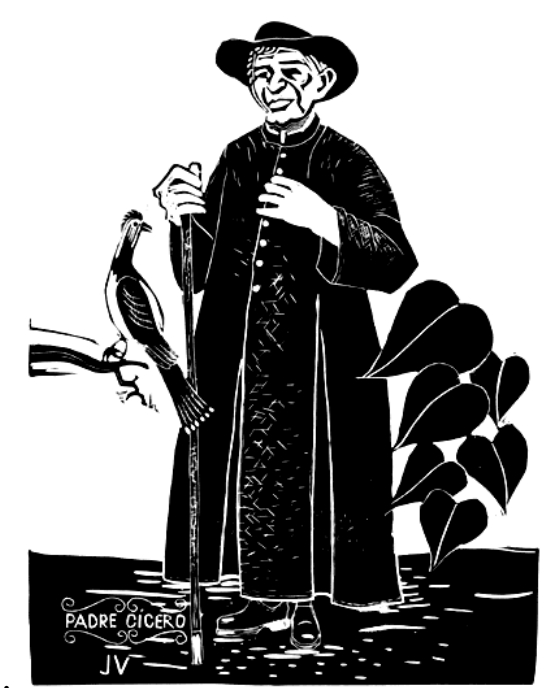

Figura: 13 - Padre Cícero

Conselheiro

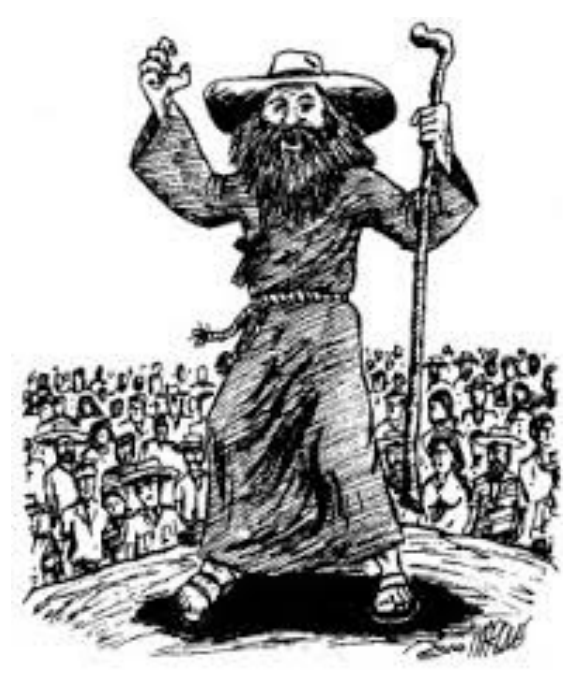

Figura:14 - Antônio 
Padre Cícero Romão Batista nasceu na cidade do Crato, Estado do Ceará, em vinte e quatro de março de mil oitocentos e quarenta e quatro. Desde muito cedo o menino Cícero demostrou inclinação para a vida sacerdotal. Por essa razão era comum encontrá-lo mergulhado em orações na igreja e a ajudar o vigário nos afazeres paroquiais.

Ingressou no Seminário, vindo a ordenar-se padre. Homem de profunda espiritualidade, logo ganhou a fama de milagreiro pelo povo. Foi suspenso da ordem, porém sua fama se espalhou e ele ganhou as graças do povo sofrido, que via no "padinho pade Cícero", como era comumente conhecido, um homem santo em vida, e após sua morte a sua lembrança continua a cada dia santo e cada santo dia, levando homens e mulheres à Cidade do Crato para fazerem e pagarem promessas a este homem que foi do povo e para o povo. Ênio Brito, afirma:

Diante de uma sociedade que não garante a vida, a ação do Padre Cícero gerava vida e resgatava Deus para o povo. Hoje, o peregrino que vem a Juazeiro se sente um eleito, a peregrinação possibilita a ele reafirmar sua identidade. (BRITO,2000, p.167).

Outra figura é Antônio Vicente Mendes Maciel, conhecido popularmente como Antônio Conselheiro, que foi um beato, líder religioso e de um dos primeiros movimentos sociais no Brasil. Nasceu em Quixeramobim (CE), em treze de março de mil oitocentos e trinta e faleceu em Canudos (BA) em vinte dois de setembro de mil oitocentos e noventa e sete.

Considerado um fora da lei pelas autoridades, Antônio peregrinava pelo sertão do Nordeste marcado pela seca, fome e miséria. Esse "religioso" levava mensagens de teor piedoso e escatológico e dava conselhos para a população carente. Conseguiu uma grande quantidade de seguidores, sendo que muitos o consideravam santo. Muitos de seus seguidores chegaram a afirmar que o beato tinha a capacidade de fazer milagres.

Antônio Conselheiro viu-se rejeitado e perseguido pela Igreja institucional e pelo Estado. A igreja recusa sua profecia e sua pregação que, segundo ela, afetava a ortodoxia e a pureza da doutrina. O Estado, por sua vez, o condenava em seu projeto sociopolítico, como um foco de agitação que subvertia a suposta calmaria da ordem 
pública, onde uma República foi proclamada pelo Exército, sem a participação popular, enquanto Conselheiro era defensor da Monarquia.

Antônio Conselheiro

Cada um na vida tem

$\mathrm{O}$ direito de julgar

Como tenho o meu também

Com razão quero falar

Nestes meus versos singelos

Mas de sentimentos belos

Sobre um grande brasileiro

Cearense meu conterrâneo,

Líder sensato espontâneo,

Nosso Antônio Conselheiro.

Este cearense nasceu

Lá em Quixeramobim,

Se eu sei como ele viveu

Sei como foi o seu fim,

Quando em Canudos chegou

Com amor organizou

Um ambiente comum

Sem enredos nem engodos,

Ali era um por todos

E eram todos por um.

(PATATIVA DO ASSARÉ). ${ }^{3}$

Papa Francisco, na sua Encíclica Evangelii Gaudium para os fiéis católicos, ressalva que a cultura é uma junção de múltiplas manifestações e não podemos de forma alguma isolar seus elementos constitutivos. Por outro lado, em relação às manifestações

\footnotetext{
${ }^{3}$ Excerto extraído da obra Cordéis Patativa do Assaré (1999, p. 15).
} 
da religião popular como parte da cultura de um povo, devemos ter uma visão plural e respeitar a diversidade cultural e de carismas. Ensina-nos Papa Francisco:

O Espirito Santo constrói a comunhão e a harmonia do povo de Deus. Ele mesmo é a harmonia, tal como é o vínculo de amor entre o Pai e o Filho. É ele que suscita uma abundante e diversificada riqueza de dons e, ao mesmo tempo, constrói uma unidade que nunca é uniformidade, mas multiforme harmonia que atrai. A evangelização reconhece com alegria as múltiplas riquezas que o Espírito gera na Igreja. Não faria justiça à lógica da encarnação pensar um cristianismo monocultural e monocórdico. A mensagem que anunciamos sempre apresenta alguma roupagem cultural, mas às vezes, na Igreja, caímos na vaidosa sacralização da própria cultura, o que pode mostrar mais fanatismo do que autêntico ardor evangelizador. (PAPA FRANCISCO, 2013, p.73).

\section{Do pobre para o pobre}

“A melhor forma de falar de Deus é por meio da poesia".

(Gustavo Gutiérrez)

Se estabelecermos uma comparação entre a obra de Patativa do Assaré, a literatura de folhetos nordestinos e a religiosidade popular, será possível observar uma relação mútua entre elas. Patativa produz uma voz profética, sendo um verdadeiro anunciador da boa-notícia aos pobres e oprimidos do sertão nordestino: sua poesia é a respeito do pobre, para o pobre e do pobre.

Sua forma de escrita não é simplesmente para chegar ao povo simples, ele escreve devido à sua cultura criadora, compõe e escreve para o seu povo na linguagem que aprendeu em seu ambiente cultural. Alfredo Bosi descreve dessa forma os tipos de cultura no Brasil:

Se pelo termo cultura entendemos uma herança de valores e objetos compartilhada por um grupo humano relativamente coeso, poderíamos falar em uma cultura erudita brasileira, centralizada no sistema educacional (e principalmente nas universidades), e uma cultura popular, basicamente iletrada, que corresponde aos mores materiais e simbólicos do homem rústico, sertanejo ou interiorano, e 
do homem pobre suburbano... A essas duas faixas extremas bem marcadas poderíamos acrescentar... a cultura criadora individualizada de escritores, compositores, artistas plásticos, dramaturgos, cineastas, enfim, intelectuais que não vivem dentro da Universidade, e que... formariam... um sistema cultural alto... Enfim, a cultura de massas, que, pela sua íntima imbricação com os sistemas de produção e mercado de bens de consumo, acabou sendo chamada pelos intérpretes da Escola de Frankfurt, indústria cultural, cultura de consumo. (BOSI, 1992, p. 309).

$\mathrm{Na}$ forma poética, Patativa abrange a questão da religião através dos símbolos populares. Ele enfatiza que o sertanejo é homem de poucas palavras, mas que sente o mundo como um pedacinho seu. Sua fé é em um Deus forte. A virgem Maria é sua companheira inseparável e os homens santos o colocam perto de Deus. A fé para o nordestino é a chama que o mantém vivo, e mesmo diante das dificuldades, acreditar é afirmar-se como vivente.

Patativa ressalta em seus poemas as injustiças sociais e econômicas feitas aos pobres nordestinos, e ele afirma que isso não é consequência do juízo de Deus, que os estaria a castigar, mas sim que é o próprio homem quem submete seu semelhante a tais condições de sofrimento e dor. Assaré grita contra toda forma de exploração e maldade contra o homem e relembra a seu modo o mandamento fundamental enunciado por Cristo: "Amarás ao Senhor teu Deus de todo o teu coração, e de toda a tua alma, e de todo o teu entendimento, e de todas as tuas forças. Amarás o teu próximo como a ti mesmo". (Mc 12.30-31).

A estratificação social coloca uma minoria de homens em patamares elevados de tal forma que uns são "donos" dos outros, mas na perspectiva da religiosidade popular o homem só deve ser julgado pelo seu Senhor e Deus, Cristo Jesus. A imagem de Deus é constante na vida do sertanejo e no seu cotidiano. Trata-se de um Deus que está do seu lado, pois preferiu os fracos, as viúvas, e o povo que labuta por sua sobrevivência.

A poética de Patativa do Assaré é messiânica e futurista, ele prevê dias e condições melhores ao seu povo. Não se esquece de onde veio e não sabe para onde vai, 
porém sempre levanta a sua voz, esbraveja por dias melhores no sertão árido e sofrido, onde a própria natureza geme e clama por Deus, como disse o profeta Joel. ${ }^{4}$

Assaré tem em Deus o Senhor da Providência, que nunca se esquecerá de nenhum de seus filhos. Neste trecho de Caboclo Roceiro Patativa descreve a vida do sertanejo que planta e confia em Deus para ter uma boa colheita.

Caboclo Roceiro, das plaga do Norte

Que vive sem sorte, sem terra e sem lar,

A tua desdita é tristonho que canto,

Se escuto o meu pranto me ponho a chorar

Ninguém te oferece um feliz lenitivo

És rude e cativo, não tens liberdade.

A roça é teu mundo e também tua escola.

Teu braço é a mola que move a cidade

De noite tu vives na tua palhoça

De dia na roça de enxada na mão

Julgando que Deus é um pai vingativo,

Não vês o motivo da tua opressão

Tu és nesta vida o fiel penitente

Um pobre inocente no banco do réu.

Caboclo não guarda contigo esta crença

A tua sentença não parte do céu.

O mestre divino que é sábio profundo

Não faz neste mundo teu fardo infeliz

As tuas desgraças com tua desordem

Não nascem das ordens do eterno juiz

(Patativa do Assaré) $^{5}$

Nesta viagem com Patativa do Assaré é demostrada sua criatividade na relação de folhetos nordestinos e religiosidade. Vê-se que o agricultor pobre, que passou por

\footnotetext{
${ }^{4}$ Joel (1.17-18) diz: "A ti, ó Senhor, clamo, porque o fogo consumiu os pastos do deserto, e a chama abrasou todas as árvores do campo. Todos os animais do campo bramam suspirantes por ti; porque os rios se secaram, e o fogo devorou os pastos do deserto".

${ }^{5}$ Excerto extraído da obra Cordéis Patativa do Assaré (1999, p. 35).
} 
grandes agruras e desgostos profundos, fez do seu aprendizado com o sertão e a enxada uma escola. E sua relação com a poesia, a mestra das mestras, o fez cantar a dor e a esperança de redenção desse povo oprimido por um sistema cruel e insensível.

\subsection{A literatura de folhetos e a religiosidade}

A literatura popular nordestina e nacional é marcada pela oralidade que a torna original. É nos improvisos e versificações que a linguagem se produz, e quando valoriza em seu conteúdo a religião do povo simples e ao mesmo tempo matuto é que se torna capaz de narrar a história e a cultura de um povo de forma completa, buscando a sua conscientização e a sua libertação com a força e a suavidade da poesia e com a inspiração de sua irmã gêmea, a música.

A poesia é uma militante do sofrer e pensar e reflete o clamar do povo pela misericórdia de um Deus que não abandona nenhum de seus filhos. Ela estabelece uma teia de genuinidade para aqueles que, com tamanha luta, sofrimento, dor e lamento, descobrem na poesia dos folhetos como se comunicar com o povo e com Deus.

Na contemplação e no entusiasmo diante da linguagem e do poder da expressão, esses poetas, como Patativa do Assaré, articularam um jeito de se comunicar. Esses homens rudes expressam de diversas formas, por meio da poesia, sua capacidade de perceber a beleza na diversidade da realidade. Abordam os conflitos pessoais, a vida em sociedade, os problemas de ordem social, política e econômica. Tratam a religião, o transcendental, de forma especial. Assim ajudam o povo a se esclarecer e a fazer sua jornada com fé e perseverança, sempre utilizando a linguagem simples, do povo simples e para o povo simples.

A oralidade é cristalizada na vida do poeta e na memória de sua gente, pois para esta a poesia é para ser dita e ouvida, sendo voz e marca preponderante de toda a sua vida. Atribuem a Deus e à natureza todo o aprendizado que Patativa e outros repentistas transferem de forma simples, pois creem que aquilo que eles aprendem, escrevem e cantam é dom de Deus e da natureza. Cabe a eles, pois, transmití-lo a todos os demais.

Eu nasci ouvindo os cantos

Das aves de minha serra

E vendo os belos encantos

Que a mata bonita encerra

Foi ali que eu fui crescendo 
Fui vendo fui aprendendo

No livro da natureza

Onde Deus é mais visível

O coração mais sensível

$\mathrm{E}$ a vida tem mais pureza.

Sem poder fazer escolhas

De livro artificial

Estudei nas lindas folhas

Do meu livro natural

$\mathrm{E}$, assim longe da cidade

Lendo nessa faculdade

Que tem todos os sinais

Com esses estudos meus

Aprendi amar a Deus

$\mathrm{Na}$ vida dos animais.

Quando canta o sabiá

Sem nunca ter tido estudo

Eu vejo que Deus está

Por dentro daquilo tudo

Aquele pássaro amado

No seu gorjeio sagrado

Nunca uma nota falhou

$\mathrm{Na}$ sua canção amena

Só canta o que Deus ordena

Só diz o que Deus mandou.

(PATATIVA DO ASSARÉ) $^{6}$

${ }^{6}$ Poema sem título encontrado na obra de Assaré. Digo e não peço segredo. 


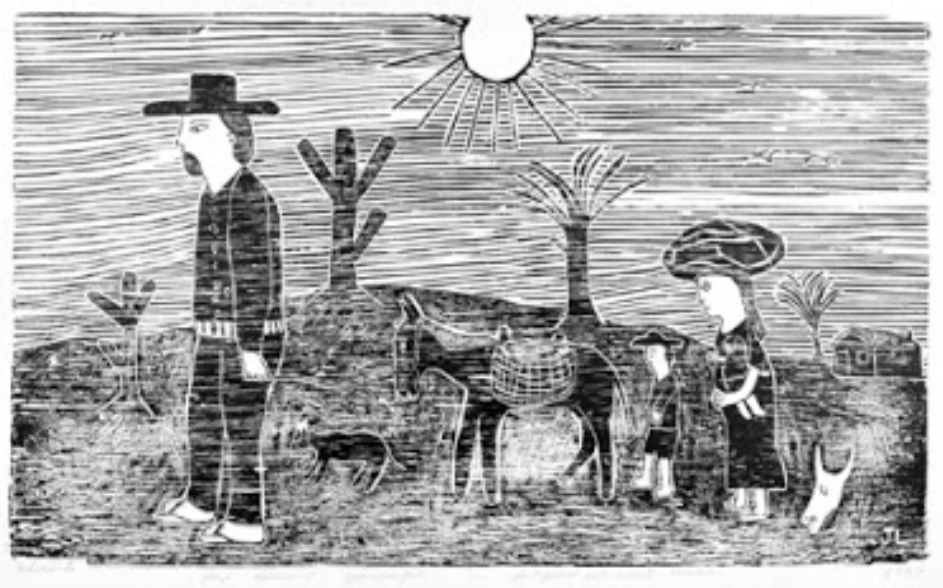

Figura 15 - Retirante (1986) - José Lourenço Gonzaga

\section{CONCLUSÃO}

É imprescindível que, diante dos argumentos expostos, todos se conscientizem de que a Literatura de folhetos nordestinos é rica de detalhes e claramente uma antologia literária. Com suas formas e traços genuínos.

O fio condutor de todo o trabalho foi desmitificar a equivocada relação que fazem da Literatura de Cordel a qual tem sua história desde os árabes, a península ibérica e posteriormente a Europa da Literatura de Folhetos Nordestinos que é legitimamente iniciada pela oralidade, através dos repentistas e só depois escrita por Leandro Gomes de Barros e outros folhetistas.

Outro traço que se nota no trabalho é a profunda relação do sertanejo com o contexto histórico. Isto dava matéria aos poetas e repentista. O objetivo foi demostrar de forma bem clara e distinta uma literatura hoje um pouco desconhecida aos nossos olhos, e que pode se perder no tempo e espaço, porém rica de criatividade e originalmente brasileira.

Uma literatura até mesmo menosprezada. Somos levados a acreditar que, por ilustríssimos autores tais como: Patativa do Assaré, Ariano Suassuna, Câmara Cascudo e outros, que a literatura de folhetos nordestinos surge das nossas raízes e é produto de nossa criatividade.

E que por sua vez a literatura de folhetos deve ser ensinada e valorizada; a educação é transmissão e devemos repassá-la para filhos, netos e bisnetos; devemos 
propagar nos quatro cantos que temos algo que é produto de nossa riqueza cultural e literária.

Que somos brasileiros e produtores de uma grande e vasta cultura literal, religiosa e musical e que a apresentação de nossa nacionalidade não seja motivo de nos envergonhamos, mas de nos envaidecermos de algo nosso. Tal e qual a Literatura de folhetos nordestinos.

\section{REFERÊNCIAS BIBLIOGRÁFICAS}

ASSARÉ, Patativa do. Inspiração Nordestina: Cantos de Patativa. Hedra, 2003.

ASSARÉ, Patativa do. Cordéis do Patativa do Assaré. Fortaleza. UFC (coleção nordestina), 1999.

ANDRADE, Cláudio Henrique Sales. Patativa do Assaré: as razões da emoção (capítulos de uma poética sertaneja). São Paulo, Nankim, 2003.

BÍBLIA. Português. A Bíblia de Jerusalém. Nova edição rev. e ampl. São Paulo: Paulus, 1985.

CASCUDO, Luís de C. Dicionário do Folclores Brasileiro.

CUNHA, Euclides da. Os sertões. Edição crítica de Walnice Nogueira Galvão. São Paulo: Ática, 1998.

55

DERPOEL, Francisco Van. Religiosidade Popular: O exemplo da milenar oração para curar a erisipela. In. Artigo Marco- Abril, 2013. Disponível em: vidapastoral.com.br

DÓRIA, Carlos Alberto. O cangaço. $2^{\mathrm{a}}$ ed. São Paulo: Brasiliense, 1981.

FRANCISCO,Papa. Evangelii Gaudium. Exortação Apostólica. São Paulo: Paulus, 2013.

GUTIÉRREZ, Gustavo. Teologia da Libertação. Petrópolis: Vozes, 1975. 
SHOKEL, Alonso; J.L., Sicre Diaz. Profetas I: Isaías, Jeremias. São Paulo: Paulus, 1988.

TEÓFILO, Rodolfo. A fome. Editoria Demócrito Rocha, 1890.

VIANA, Klévisson. Os miseráveis em cordel. São Paulo: Nova Alexandria, 2008. 